\title{
AWARENESS REGARDING HEALTH PROMOTION OF INFANTS AMONG MOTHERS OF RUPANDEHI, NEPAL
}

Kavita Lamichhane, ${ }^{1}$ Swetha Maharjan, ${ }^{1}$ Anuja Kachapati ${ }^{1}$

\section{ABSTRACT}

\section{INTRODUCTION}

Health promotion of infancy is necessary for the optimum growth and development. Mother is significant person for the promotion of health of infant.

\section{MATERIAL AND METHODS}

Descriptive cross-sectional study was conducted to find out the awareness regarding health promotion of infants among 78 mothers in Bhim Hospital of Siddharthanagar Municipality by using purposive sampling technique. Semistructured interview schedule was used to collect data and analyzed by using descriptive and inferential statistics with SPSS version 20.

\section{RESULTS}

The study findings revealed that $51.3 \%$ of the respondents have low level of awareness regarding health promotion of an infant. There was statistically significant association between respondents' level of awareness with occupation and respondents' husband's age.

\section{CONCLUSION}

The study concluded that more than half of the mothers have low level of the awareness regarding health promotion of the infant. Mothers' occupation and husbands' age are the influencing factors on mothers' knowledge regarding health promotion of infant.

KEYWORDS Awareness, Infant, Health promotion

1. Universal College of Nursing Sciences, UCMS, Bhairahawa, Nepal

DOI: http//doi.org/10.3126/jucms.v8i1.29839

For Correspondence

Ms. Kavita Lamichhane

Universal College of Nursing Sciences

UCMS

Bhairahawa, Nepal

Email:lamichhanekavita@gmail.com 


\section{INTRODUCTION}

Infancy is a period of rapid physical and mental development as well as cognitive development. So infancy period is considered as critical age in the childhood. During this period, their imitation and dependency on a person who takes care of them are very strong. Therefore, a mother who provides an infant with care acts as an active and primary participant in maintaining and promoting health of the child.' Health promotion of the infants is best done by the fulfilment of physical and physiological needs through breast feeding, complementary feeding, immunization, growth monitoring and safety precaution for prevention of accidents. ${ }^{2}$

Globally, the infant mortality rate has decreased from 65 deaths per 1000 live births in 1990 to 29 deaths per 1000 live births in 2017. Annual infant deaths have declined from 8.8 million in 1990 to 4.1 million in 2017 . $^{3}$ In Nepal, Infant mortality has decreased by more than half from 78 deaths per 1000 live births in 1996 to 32 in $2016 .{ }^{4}$ The child health status depends upon the mothers' knowledge, attitude and practice regarding knowledge of health promotion as child care is mostly the responsibility of mothers. If we increase the awareness of promotion of health among mothers who have infant, we will be able to succeed to decrease the infant's mortality rate. Objectives of this study was to identify the awareness regarding health promotion of infant among mothers and to find out association between level of awareness regarding health promotion with their sociodemographic variables

\section{MATERIAL AND METHODS}

A descriptive cross-sectional research design was used to find out the awareness regarding health promotion of infant among 78 mothers by using non-probability purposive sampling technique. The study was conducted in Maternal and Child Health Clinic (MCH) of Bhim Hospital of Siddharthanagar municipality-13, Rupandehi district, Province-5, Nepal. Semi structured interview schedule was used for data collection within two weeks period during the month of September, 2019. A descriptive statistics and inferential statistics (chisquare tests) were used to find out the association between level of awareness and their socio- demographic variables with SPSS version 20. Ethical and administrative approval was obtained from the concerned authorities prior to data collection. Written informed consentwas obtained from each respondent by clarifying the objective of the study.

\section{RESULTS}

Nearly half of the respondents (42.30\%) were in the age group $20-24$ years, $79.48 \%$ were Madhesi, $85.9 \%$ were Hindu. Most of the respondents were literate $(85.9 \%)$ and home maker
(82.1\%), $56.4 \%$ of respondents have only one child, $43.6 \%$ have more than one child and $47.4 \%$ have $1-3$ month of infant and $25.6 \%$ have $7-9$ month of infant at home and $44.9 \%$ were living in joint family. All the respondents have delivered their baby in hospital. Most of the respondents' husbands (70.5\%) were in the age groups $20-30$ years and literate $(86.3 \%)$. Regarding husband's occupation, $58.98 \%$ of the respondents' husbands were service provider.

Table 1. Respondents' awareness regarding breastfeeding

\begin{tabular}{lcr}
\hline Variables & $\begin{array}{c}\text { Frequency } \\
(\mathrm{n}=78)\end{array}$ & Percentage \\
\hline Meaning of breastfeeding & & \\
Feeding mother's milk* & 66 & 84.60 \\
Caring of infant & 11 & 14.10 \\
Adding /Feeding powder milk & 1 & 1.30 \\
Meaning of exclusive breastfeeding & & \\
Feeding breast milk only for 6 month* & 67 & 85.90 \\
Feeding breast milk and water for 6 months & 11 & 14.10 \\
& & \\
Benefits of breastfeeding & & \\
To baby & 70 & 89.70 \\
$\quad$ Provides immunity* & 26 & 33.30 \\
Protects from allergies* & 14 & 17.90 \\
Protects from diabetes & 76 & 97.40 \\
Better health and less risk of illness* & 13 & 16.70 \\
Cures pneumonia & & \\
& & \\
To mother & 13 & 16.70 \\
Weight gain & 48 & 61.50 \\
Prevents from breast cancer* & 76 & 97.40 \\
Strengthen relationship between & & \\
mother and baby* & 21 & 26.90 \\
Protects from allergies & 38 & 38.50 \\
Saves money* & & \\
Delays pregnancy* & & \\
\hline
\end{tabular}

*Correct response; **Multiple responses

Majority of the respondents (85.9\%) answered the meaning of exclusive breast feeding as feeding breast milk only for 6 months. With regards benefits of breastfeeding to baby, $97.4 \%$ of respondents answered better health and less risk of illness and $17.9 \%$ of respondents answered protects from diabetes whereas $97.4 \%$ of respondents answered breastfeeding strengthen the relationship between mother and baby and $16.7 \%$ of respondents answered weight gain as benefit of breastfeeding to mother.

More than half (56.4\%) of respondents answered two year and $3.8 \%$ of respondents answered one year as minimum period for breastfeeding. 
Table 2. Respondents' awareness regarding complementary feeding

\begin{tabular}{lcc}
\hline Variables & $\begin{array}{c}\text { Frequency } \\
(\mathbf{n}=78)\end{array}$ & Percentage \\
\hline Meaning & & \\
$\quad$ Introduction of only semisolid food & 03 & 3.80 \\
$\quad$ Introduction of semi-solid and solid food & 74 & 94.90 \\
$\quad$ along with breastfeeding* & & \\
$\quad$ Adding formula milk & 01 & 1.30 \\
Initiation & & \\
5 months of age & 04 & 5.10 \\
6 months of age* & 62 & 79.50 \\
7 months of age & 07 & 9.00 \\
8 months of age & 05 & 6.40 \\
Items of complementary feeding** & & \\
Khichri* & 62 & 79.50 \\
Litto (super-flour)* & 70 & 89.80 \\
Cows/buffalos milk* & 36 & 46.20 \\
Soft drinks & 06 & 7.70 \\
Fried potatoes & 06 & 7.70 \\
\hline
\end{tabular}

*Correct response; **Multiple responses

Majority (94.9\%), (79.5\%) respondents answered meaning of complementary feeding and initiation of complementary feeding at 6 months of age respectively. Regarding food items of complementary feeding, $79.5 \%, 89.9 \%$ and $46.2 \%$ answered khichri, litto and cows/buffalos milk respectively.

Table 3. Respondents awareness regarding immunization

\begin{tabular}{|c|c|c|}
\hline Variables & $\begin{array}{c}\text { Frequency } \\
n=78\end{array}$ & Percentage \\
\hline \multicolumn{3}{|l|}{ Meaning* } \\
\hline Cures disease & 5 & 6.40 \\
\hline $\begin{array}{l}\text { Develops resistance to } \\
\text { infectious disease* }\end{array}$ & 53 & 67.90 \\
\hline Protect from mental illness & 1 & 1.30 \\
\hline \multicolumn{3}{|l|}{ Disease prevents by BCG vaccine } \\
\hline Tuberculosis & 35 & 44.90 \\
\hline \multicolumn{3}{|l|}{ Frequency of OPV } \\
\hline Giving OPV for 3 times & 51 & 65.40 \\
\hline \multicolumn{3}{|l|}{ Timing of Measles vaccine } \\
\hline 9 months completion & 60 & 76.90 \\
\hline \multicolumn{3}{|l|}{ Frequency of DPT HepB, Hib Vaccine } \\
\hline Giving DPT HepB, Hib Vaccine for 3 times & 51 & 65.40 \\
\hline \multicolumn{3}{|l|}{ Disease prevents by DPT НерB, Hib vaccine } \\
\hline $\begin{array}{l}\text { Diptheria, Pertussis, Tetanus, Hepatitits B, } \\
\text { Hemophilus Influenza B }\end{array}$ & 33 & 42.30 \\
\hline \multicolumn{3}{|l|}{ Care after DPT HepB, Hib Vaccination } \\
\hline Apply hot compression & 1 & 1.30 \\
\hline Apply cold compression* & 74 & 94.90 \\
\hline Massage the injection site & 3 & 3.90 \\
\hline \multicolumn{3}{|l|}{ Common problems after immunization } \\
\hline Fever & 69 & 89.00 \\
\hline Vomiting & 2 & 2.60 \\
\hline Cough & 3 & 3.80 \\
\hline Redness and inflammation & 59 & 75.70 \\
\hline
\end{tabular}

**Multiple responses; ${ }^{*}$ Correct response

Note: DPT, Hepatiti B and Hib were taken as single vaccines or as in PENTAVALENT

Most (67.9\%) of respondents answered that immunization develops resistance to infectious diseases as meaning of immunization. Regarding common problems after immunization, $88.5 \%$ of respondents answered fever and $2.6 \%$ answered redness and inflammation as the common problem of immunization.

\begin{tabular}{lrr}
\hline Home Accident & $\begin{array}{c}\text { Frequency } \\
\mathrm{n}=78\end{array}$ & Percentage \\
\hline Major types of home accident** & & \\
Suffocation* & 39 & 50.00 \\
Poisoning & 2 & 2.60 \\
Burns & 14 & 17.90 \\
Choking & 37 & 47.40 \\
Drowning & 7 & 9.00 \\
Falls* & 54 & 69.20 \\
Causes** & & \\
Unmanaged environment* & 67 & 85.90 \\
Managed environment & 1 & 1.30 \\
Doing work with handling baby* & 65 & 83.30 \\
Lack of supervision* & 28 & 35.90 \\
$\quad$ Poverty & 13 & 16.70 \\
Preventive measures** & & \\
$\quad$ Never leave infant alone* & 76 & 97.40 \\
Proper lighting* & 23 & 29.50 \\
Keep all plastic bags near to & 2 & 2.60 \\
Do not cover the face by cloth* & 33 & 42.30 \\
Keep hazardous things out of reach* & 68 & 87.20 \\
\hline *orrect response; * Multiple response & &
\end{tabular}

More than half (69.2\%) of respondents answered falls and $50 \%$ respondents answered suffocation as the major types of home accidents. Regarding causes of home accidents, 85.9\% and $83.3 \%$ of respondents answered unmanaged environment and doing work with handling baby. Regarding preventive measures of home accident, $97.4 \%$ of the respondents answered as infant should never be left alone and $2.6 \%$ of respondents answered as keeping all plastic bags near.

Regarding milestones, $33.3 \%$ of respondents answered infant sit with support at 6 months, and $79.5 \%$ of respondents answered infant stand with support at 9 months and $88.5 \%$ of respondents answered infant walk by holding one hand at 12 months. Nearly half (44.9\%) of respondents answered approximate sleeping hour of infant is 12 hours and $14.1 \%$ of respondents answered approximate sleeping hours of infant is 14 hours.

Table 5. Overall awareness regarding health promotion of infant

\begin{tabular}{lcc}
\hline Level of Awareness & Frequency $(\mathbf{n}=78)$ & Percentage \\
\hline High & 38 & 48.70 \\
Low & 40 & 51.30 \\
Total & 78 & 100 \\
\hline
\end{tabular}

Mean score $=17.92 ;$ Total score $=31$

More than half $(51.3 \%)$ of respondents had low level of awareness regarding health promotion of infant. 
There was statistically significant association between respondents' occupation $(p=0.018)$ and husbands' age $(p=0.03)$ and level of awareness.

\section{DISCUSSION}

The study findings showed that $97.4 \%$ of respondents were aware that breastfeeding helps to promote better health and reduce risk of illness which is consistent with the study of Dhammika and Gunauardena (2012) conducted in Sri Lanka showed that $99.5 \%$ of respondents were aware of the benefit of breastfeeding as to promote better health and less risk of illness. $^{5}$

The present study shows $85.9 \%$ were aware of meaning of exclusive breastfeeding as feeding only breast milk for 6 months, $89.7 \%$ and $33.3 \%$ were aware that breastfeeding provides immunity and protects from allergies as benefit of breastfeeding to baby which is not consistent with the study of Dhammika and Gunauardena (2012) conducted in Sri Lanka showed that $100 \%$ of respondents were aware of meaning of exclusive breastfeeding and $99.5 \%$ and $84.3 \%$ of respondents were aware of benefits of breastfeeding. ${ }^{5}$

This study showed that $56.47 \%$ of the respondents were aware that minimum period of breastfeeding is upto two years which is not consistent with study finding of Abroo, Suahil and Mohammad (2018) conducted in India which revealed 83.3\% of the mothers knew breastfeeding to be continued for 2 years. $^{6}$

The study findings showed that $79.5 \%$ of the respondents were aware of the initiation of complementary feeding is six months which is not consistent with the study of Kandel et al (2016) conducted in Nepal which showed $73.8 \%$ of respondents were aware of the initiation of complementary feeding is six months.

The study results showed that $97.4 \%$ of the respondents were aware that immunization protects from diseases which are supported by the study of Gul and Khali (2016) conducted in Pakistan which revealed $97 \%$ of the mothers were aware that immunization protects the child from diseases. ${ }^{8}$ The study findings showed that $88.5 \%$ of the respondents were aware that fever is also one of the common problems of immunization which is not supported by the study finding of Kapoor and Khan (2015) conducted in India which showed $60 \%$ of the respondents were aware that fever as the common problem of immunization. ${ }^{9}$

Present study's findings showed $50 \%$ of the respondents were aware of suffocation as a major type of home accident. Likewise, $69.2 \%$ were aware that fall is also the major type of home accident which is consistent with the study finding of
Adhikari et al (2017) conducted in Nepal showed that $67.8 \%$ of the respondents aware of the major type of home accident is fall. $^{10}$

In this study, $35.9 \%$ of the respondents were aware that lack of supervision is the causes of home accident which is not consistent with study findings of Adhikari et al (2017) conducted in Nepal showed that $96.6 \%$ of the respondents were aware that lack of supervision can cause home accident of infant. ${ }^{10}$

Similarly, the study reveals that $87.2 \%$ of the respondents were aware that hazardous things should be keep out of reach of infant for prevention of the home accident which is not consistent with study finding of the Sachiktey (2017) conducted in Ghana which showed that $80 \%$ of the respondents were aware of the prevention of home accident by keeping hazardous things out of reach of infant. ${ }^{11}$

It has been found that $33.3 \%$ and $79.5 \%$ of the respondents were aware that from 6 months the baby can sit with support and from 9 months baby can stand with support respectively which is not consistent with the finding of the study of Rehman et al (2016) conducted in a Pakistan which showed that $56.38 \%$ and $60.8 \%$ of respondents were aware that infant can sit with support in six months and stand in nine months. ${ }^{12}$

The present study showed that there was no statistically significant association of respondents' level of awareness with age ( $p=0.08)$ which is consistent with the study finding of Adhikari et al (2017) conducted in Nepal which showed no statistically significant association of respondents level of awareness with age $(p=0.31) .^{10}$

The study findings showed that there was statistically significant association of respondents' level of awareness with occupation of respondents $(p=0.01)$ which is not consistent with the study finding of Akturk (2012) conducted in Turkey which showed statistically significant association of respondents level of awareness with education of respondents $(p=0.01) .^{13}$ The study findings showed that there was statistically significant association of respondents level of awareness with husbands' age $(p=0.03)$.

\section{CONCLUSION}

Based on the study findings, it is concluded that $48.7 \%$ of mothers have high level of the awareness among 78 mothers regarding health promotion of the infant. Infancy is a period of rapid physical and mental development as well as cognitive development. So, infancy period is considered as critical age in the childhood. Therefore, child care is mostly responsibility of mother. Hence, mothers' knowledge about child care influences the nature and quality of care that is given to the 
child. Therefore, there is utmost need to increase the mothers' knowledge to provide optimum care to the child.

\section{ACKNOWLEDGEMENT}

Researchers deeply express their heartfelt thanks to all mothers who participated in the study for immense support and cooperation. Researchers express their deep and sincere gratitude to all those experts for their valuable judgment, constructive feedbacks and enlightening suggestions through out the study.

\section{REFERENCES}

1. Lee K, Moon H, Han Y, Lim S. The Factors affecting Health Behaviors of a Mother with Infants and Toddlers. Indian Journal of Science and Technology. 2015;8(35):1-9

2. Datta, P. (2014). Pediatric nursing. 3rd ed. New Delhi: Jaypee Brothers Medical Publishers, p.134

3. Infant mortality World Health Organization. 2019.

4. Nepal Demographic and Health Survey. Dhs program.com. 2019.

5. Dhammika B, Gunawardena N. Knowledge, practices and concerns regarding exclusive breastfeeding for six months among mothers of infants in a suburban setting in Sri Lanka. Sri Lanka Journal of Child Health. 2012;41(1):9-14.

6. Bashir A, Mansoor S, Naikoo M. Knowledge, attitude, and practices of postnatal mothers regarding breastfeeding: A crosssectional study. International Journal of Medical Science and Public Health. 2018;7(9):725-730.

7. Kandel K, Sah B, Kafle S, Khanal S, Adhikari B. Factors affecting complementary feeding among mothers of under two years children in Darai and Kumal communities of Mangalpur, Chitwan. Journal of Chitwan Medical College. 2016; 6 (18) :2430

8. Gul S, Khalil R. Immunisation knowledge and practices among mothers attending a paediatric clinic in Karachi, Pakistan. International Journal of Advances in Medicine. 2016;3(3):656661.

9. Khan A, Kapoor A. Beliefs and practices among mothers regarding immunization. Peoples College of Medical Sciences and Research Centre. 2015;9(1):53-56.

10. Adhikari B, Bhattrai S, Gauro P, Mishra R. Awareness and practice of mother having under 5 children regarding prevention of childhood accident. International Journal of Health Sciences and Research. 2017;7(9):134-144.

11. Sachiktey G. 1. Knowledge, attitude and perception on prevention of home accidents among mothers who came to the pediatrics department of the Korle $\mathrm{Bu}$ Teaching Hospital. Journal of Health Education Research and Development 2016;6(1):242-248.
12. Rehman A.U, Kazmi S.F, Munir F. Mother's Knowledge about child development. A Journal of Pakistan Pediatric Association. 2016;40(3):176-181.

13. Aktruk U. Determination of knowledge, attitude and behaviour regarding factors causing home accident and prevention in mothers with a child aged 0-5 years. Journal of Education and Practice. 2016;7(8):142-143. 